\title{
SEMMIILIEROS $\mathbb{A} \mathbb{N} D\|\| \mathbb{N}$
}

\section{Pereira, No. 12 Vol. 12 \\ Octubre 2019}

\section{AREPNDINA}

Fundación Universitaria del Área Andina

MIEMBRO DE LA RED

ILUMNO 



\section{CUADERNO DE

Pablo Oliveros Marmolejo †

Gustavo Eastman Vélez

Miembros Fundadores

Diego Molano Vega

Presidente de la Asamblea General y Consejo Superior

José Leonardo Valencia Molano

Rector Nacional y Representante Legal

Felipe Baena Botero Rector seccional Pereira

Martha Patricia Castellanos Saavedra

Vicerrectora Nacional Académica

Ana Karina Marín Quirós

Vicerrectora Nacional de Experiencia Areandina

María José Orozco Amaya

Vicerrectora Nacional de Planeación y Calidad

Darly Escorcia Saumet

Vicerrectora Nacional de Crecimiento y Desarrollo

Erika Milena Ramírez Sánchez Vicerrectora Nacional Administrativa y Financiera

María Angélica Pacheco Chica Secretaria General

Luis Alfonso Lizcano Higuera

Decano Facultad de Ciencias Jurídicas

Jackeline Marín Tapias

Decana Facultad de Ciencias de la Salud

Omar Eduardo Peña Reina Director Nacional de Investigaciones

Sandra Lorena García Henao

Subdirectora Oficina de Investigación Seccional Pereira

María Victoria Escobar González

Coordinadora Investigación Formativa Coordinadora y Revisora de Estilo Cuaderno de Investigaciones.

SEMILLEROS ANDINA

David Serna Rodríguez

Profesional de apoyo

Clara Inés Guevara Salazar

Diseño

Virginia Aristizábal P. 
Los artículos que aparecen en esta publicación fueron elaborados por estudiantes con el apoyo de docentes de la Fundación Universitaria del Área Andina, seccional Pereira, integrantes de Semilleros de Investigación, adscritos a la Red Regional de Semilleros de Investigación RREDSI.

Los textos publicados en esta revista pueden ser reproducidos citando la fuente.

investigaciones@funandi.edu.co

Pereira, Colombia

Octubre, 2019 


\section{Contenido}

Evaluación microbiológica de las ambulancias

de un Hospital en el departamento de Caldas, 2018.

Balance y simetría de la fuerza isométrica del hombro en nadadores

del Club Flamingo de natación de la ciudad de Pereira.

Características clínicas perioperatorias en pacientes drogadictos en Pereira,

Colombia: Una serie de casos.

Relación entre trastorno de ansiedad por separación e indicadores de conflicto emocional en la figura del test del árbol de niños y niñas hijos de padres separados residentes en Risaralda...

Hábitos alimenticios y riesgo cardiovascular

en el Corregimiento de La Florida, Risaralda 2018.

Aprendizaje significativo en estudiantes

que atienden el parto empleando un escenario virtual

Apreciaciones sobre la funcionalidad familiar en personas desmovilizadas de grupos armados insurgentes asentadas en el Eje Cafetero

Motivos que inducen al consumo de marihuana en estudiantes universitarios,

como fundamento para el cuidado enfermero.

Efecto de un programa de bipedestación con estabilizador distal sobre el equilibrio

estático y dinámico en bípedo en un caso de parálisis cerebral. Pereira, 2019.

Relación entre niveles de funcionalidad familiar y percepción de la calidad de vida en madres cabeza de familia habitantes de barrios vulnerables de la ciudad de Pereira

Funcionalidad familiar y

calidad de vida en familias con y sin canes

Cambios en la funcionalidad del paciente crítico y la calidad de vida

después de cuidado intensivo (UCI), Pereira 2019

El contador público: formado desde

la ética y la responsabilidad social empresarial

Correspondencia entre la dosis efectiva del cristalino

calculada con dosímetro de tórax y dosímetro ocular. 


\section{\begin{tabular}{l|l} 
AREPRNDINP & MEEMBR DE LARED \\
ILUMNO
\end{tabular}}

Riesgo de apnea obstructiva del sueño en pacientes quirúrgicos de una institución de salud, Pereira, 2019

Depresión en el personal de custodia y vigilancia de un establecimiento penitenciario de mediana seguridad y carcelario, 2019.

Representaciones sociales del autoexamen de mama en mujeres adultas de zonas rurales de Risaralda

El streaming como medio de supervivencia para la Radio.

Caso "emisora La Voz de Pereira".

Pereira desde los imaginarios de salud y actividad física

de los usuarios de la vía activa, 2019

Relevancia del E-commerce para el sector confecciones de la ciudad de Pereira..

Consumo de Marihuana y Deterioro Cognitivo en Estudiantes Universitarios,

Pereira 2019

Las percepciones sociales y el consumo de esteroides anabólicos

en usuarios de gimnasios en la ciudad de Armenia, 2019.

Efectos del tape dinámico en la función dinámica y estática del tobillo en

mujeres con características de pie pronador. Pereira 2019

Estimación del tiempo y procedimientos requeridos para la atención

con calidad en Terapia Respiratoria en servicios asistenciales del Eje Cafetero, 2019

Aprendizaje en semiología radiológica para Tecnólogos en Radiología

de la Fundación Universitaria del Área Andina, mediante una herramienta informática.

La historia de la radio en Pereira.

Caso "Emisora la Voz de Pereira"

Prevalencia del dolor músculo-esquelético en los Tecnólogos

en Radiología e Imágenes Diagnósticas

Manejo oportuno de paciente con hipoplasia maxilar y agenesia dental.

Reporte de Caso Clínico 


\section{SobreVIVIENdo al aUla del SIGLO XXI}

La educación en el siglo XXI debe brindar a los estudiantes las habilidades que precisan, para lograr el desarrollo y alcanzar el éxito en esta nueva etapa de la humanidad, puesto que se cuenta con apoyos para aumentar su confianza en la práctica de sus destrezas, gracias a la gran cantidad de información disponible, lo cual exige que esas habilidades se centran más en dar sentido a la información, compartirla y usarla de manera inteligente.

Debemos contemplar cuatro componentes importantes para el aula del siglo XXI: Creatividad, se trata de pensar la información de nuevas maneras, hacer diferentes conexiones, y encontrar soluciones innovadoras a los problemas. El Pensamiento Crítico, para analizar información y criticar afirmaciones. La Comunicación, es razonar las cosas lo suficientemente bien, como para compartirlas claramente con otras personas, y la Colaboración, se trata del trabajo en equipo y el ingenio colectivo de un grupo, que va más allá de la suma de sus partes.

Hay otras habilidades que son importantes y se encuentran dentro de estas cuatro áreas: El emprendimiento, puede considerarse una habilidad propia; la investigación y resolución de problemas, son clave; la inteligencia emocional (EQ), como una de las más importantes para el trabajo, y las relaciones exitosas.

Hoy las nuevas tecnologías pueden ayudar a sembrar las semillas del intelecto en la sociedad. Internet y la nueva era digital ofrecen un paradigma que antes era desconocido: conocimiento universal y aprendizaje a través de sistemas de e-learning, enseñanza en cursos en línea masivos y abiertos (también conocidos como MOOC). Al mismo tiempo, los nuevos equipos intentan parecerse a los recursos tradicionales: las pizarras digitales interactivas se usan de la misma manera que las pizarras clásicas, las tabletas, usadas como libros de trabajo o las computadoras portátiles como medio para los nuevos libros digitales.

En la llamada Sociedad del Conocimiento, somos bombardeados con información de las regiones más distantes del mundo difundida rápidamente a través de Internet, sitios web especializados, medios de comunicación y revistas, que tratan temas que antes solo se encontraban en publicaciones científicas. Dicha información, mientras nos actualiza, deja una sensación de impotencia para mantenerse al día con todo lo que sucede, aún si nos restringimos a nuestra área de especialización. 
Es por ello que a través de esta publicación: 'Cuaderno de Investigaciones. SEMILLEROS ANDINA', proponemos reflexionar sobre las consecuencias de los cambios en la sociedad, traídos por la tecnología al trabajo académico en la universidad, que requieren innovaciones profundas en la cultura organizacional, y para que estos cambios sucedan, es necesario, como mínimo, apertura, diálogo, intercomunicación y asociación con las más diversas fuentes de producción de conocimiento; revisión y rediseño de bases de datos e información; implementación de nuevos procesos de información y comunicación.

Se hace necesario abordar el tema de obtención del conocimiento de una manera diferente, para lo cual todos debemos prepararnos cotidianamente, con el fin de avanzar en el desarrollo social, económico y tecnológico de nuestras regiones, el País, y contribuir de esta manera al desarrollo del planeta.

Germán Oved Acevedo Osorio

Mgs. En salud Publica y Desarrollo Social. Esp. En Epidemiología

Prof. Instrumentación Quirúrgica. 


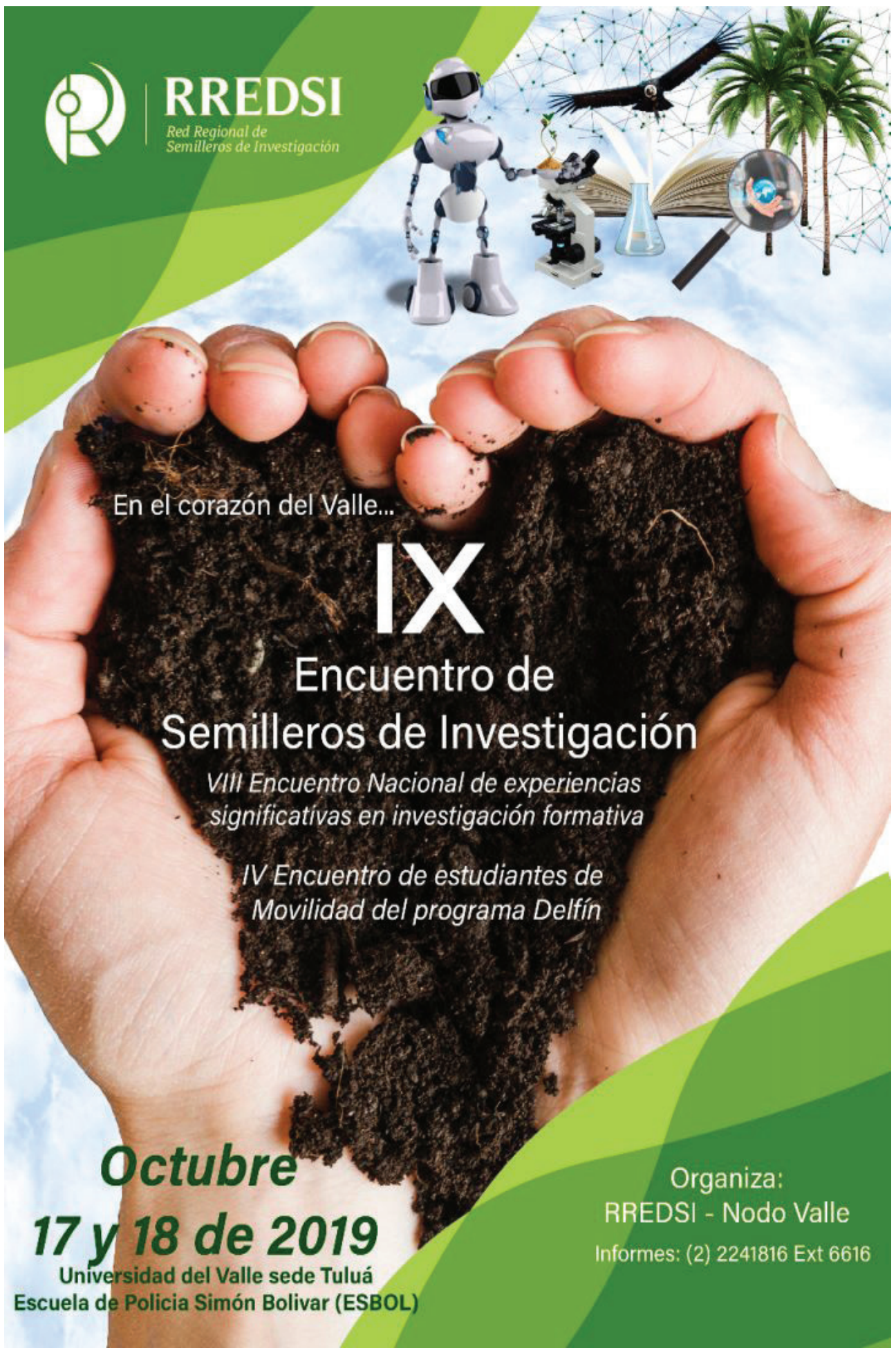

